\title{
CENÁRIO DO ATENDIMENTO EDUCACIONAL ESPECIALIZADO AOS ALUNOS SURDOS NAS ESCOLAS PÚBLICAS DO MUNICÍPIO DE URUÇUÍ-PI
}

\author{
ESCENARIO DE ASISTENCIA EDUCATIVA ESPECIALIZADA PARA \\ ESTUDIANTES DE AF EN ESCUELAS PÚBLICAS EN EL MUNICIPIO DE \\ URUÇUÍ-PI
}

\section{SCENARIO OF SPECIALIZED EDUCATIONAL ATTENDANCE FOR DEAF STUDENTS IN PUBLIC SCHOOLS IN THE MUNICIPALITY OF URUÇUÍ-PI}

\author{
Felix Gomes da Costa ${ }^{1}$; Vanessa Sousa da $\operatorname{Costa}^{2}$; Isabela de Sá Costa Sousa ${ }^{3}$; Miguel \\ Antônio Rodrigues ${ }^{4}$
}

DOI: https://doi.org/10.31692/978-65-991061-3-2.91-106

\section{RESUMO}

Durante muito tempo as pessoas surdas foram tratadas como seres humanos improdutivos, cujo encaminhamento de integração à sociedade estava voltado para o oralismo. No Brasil, somente em 2002 foi assegurada em legislação específica a Língua Brasileira de Sinais como a primeira língua dos surdos, sendo a língua portuguesa a segunda. Atualmente as instituições de ensino devem ofertar serviços educacionais especializados voltados à integração dos surdos no ambiente escolar. Este estudo teve como objetivo analisar o espaço escolar das Escolas Públicas do Município de Uruçuí-PI quanto à estrutura física e de pessoal para o suporte aos alunos surdos, associando essa estrutura ao acesso, permanência e êxito desses estudantes. A pesquisa foi desenvolvida através da aplicação de questionários semiestruturados aos gestores das nove escolas públicas localizadas na zona urbana de município de Uruçuí-PI. Os resultados mostraram que os alunos surdos são matriculados nessas escolas, porém o acompanhamento com suporte de pessoas e com estrutura tecnológica para a inclusão efetiva desse público não acontece da forma como reza a legislação, como se verificou que não existe intérprete de libras nas salas de aulas onde há pessoas surdas matriculadas. Da mesma forma, foi constatado que não existe na configuração dessas escolas ações positivas suficientes para promover a inclusão dos alunos surdos; o que as escolas fazem é apenas promover o aluno para o ano seguinte sob a alegação de amparo legal assistido a esses alunos, o que mostra desconhecimento da complexidade do processo de ensino-aprendizagem, o qual deve ocorrer de forma gradativa em todas as dimensões do ser humano.

Palavras-Chave: surdo, suporte, libras, inclusão.

\section{RESUMEN}

Durante mucho tiempo, las personas frugales fueron tratadas como seres humanos improductivos, cuya referencia a la integración en la sociedad fue condenada en el oralismo. En Brasil, en 2002, el idioma del idioma brasileño como primer idioma de los sordos estaba

\footnotetext{
${ }^{1}$ Acadêmico do curso de Licenciatura em Ciências Biológicas, campus Uruçuí do Instituto Federal de Educação, Ciência e Tecnologia do Piauí, e-mail: felixcosta518@gmail.com

${ }^{2}$ Acadêmica do curso de Licenciatura em Ciências Biológicas, campus Uruçuí do Instituto Federal de Educação,

Ciência e Tecnologia do Piaú, e-mail: sousavanessac19@gmail.com

${ }^{3}$ Acadêmica do curso de Licenciatura em Ciências Biológicas, campus Uruçuí do Instituto Federal de Educação, Ciência e Tecnologia do Piauí, e-mail: isabela7324@gmail.com

${ }^{4}$ Professor mestre do campus Uruçuí do Instituto Federal de Educação, Ciência e Tecnologia do Piauí, e-mail: miguel.rodrigues@ifpi.edu.br
} 
garantizado en una legislación específica. En la actualidad, las instituciones educativas tienen que ofrecer servicios educativos especializados para la integración de las personas sanas en el entorno escolar. Este estudio tuvo como objetivo analizar el espacio escolar de las Escuelas Públicas de Uruçuí-PI con respecto a la estructura física y personal para apoyar a los estudiantes sordos, asociando esta estructura con el acceso, la permanencia y el éxito de estos estudiantes. La investigación se desarrolló mediante la aplicación de cuestionarios semiestructurados a los gerentes de las nueve escuelas públicas ubicadas en el área urbana de Uruçuí-PI. Los resultados mostraron que los estudiantes sordos están matriculados en estas escuelas, pero el apoyo con las personas y la estructura tecnológica para la inclusión efectiva de este público no sucede como lo dice la ley, ya que se encontró que no hay un intérprete de libras en las aulas. clases donde hay personas sordas matriculadas. De manera similar, se encontró que no hay suficientes acciones positivas en la configuración de estas escuelas para promover la inclusión de estudiantes sordos; Lo que hacen las escuelas es simplemente promocionar al estudiante al próximo año por asistencia legal asistida a estos estudiantes, lo que demuestra la falta de conocimiento de la complejidad del proceso de enseñanza-aprendizaje, que debería ocurrir gradualmente en todas las dimensiones de la escuela ser humano.

Palabras clave: sordos, apoyo, libras, inclusión.

\begin{abstract}
For a long time deaf people were treated as unproductive human beings whose mainstreaming towards society. In Brazil, only in 2002 the Brazilian Sign Language as the first language of the deaf was ensured in specific legislation.. Currently educational institutions must offer specialized educational services aimed at the integration of deaf people in the school environment. This study aimed to analyze the school space of the Public Schools of the Municipality of Uruçuí-PI regarding the physical and staff structure to support deaf students, associating this structure to access, permanence and success of these students. The research was developed through the application of semi-structured questionnaires to the managers of the nine public schools located in the urban area of Uruçuí-PI. The results showed that deaf students are enrolled in these schools, but the support with people and technology structure for the effective inclusion of this public does not happen as the law says, as it was found that there is no interpreter of pounds in the classrooms. classes where there are deaf people enrolled. Similarly, it was found that there are not enough positive actions in the configuration of these schools to promote the inclusion of deaf students; What the schools do is just promote the student to the next year on the grounds of legal assistance assisted to these students, which shows lack of knowledge of the complexity of the teaching-learning process, which should occur gradually in all dimensions of the school human being.
\end{abstract}

Key words: deaf, support, pounds, inclusion.

\title{
INTRODUÇÃO
}

A inclusão de pessoas deficientes nas instituições de ensino tem sido alvo de pesquisas e discussões em nível mundial devido à falta de efetividade do processo, principalmente porque as políticas direcionadas ao atendimento desse pública não estão sendo colocadas em prática na grande parte das instituições de ensino, o que direciona para a necessidade de questionamentos que visem a mobilização do poder público e da sociedade para buscarem ações que possam melhorar esse cenário.

Dados do Censo Escolar 2018 (INEP/MEC, 2019) revelaram aumento de 33,2\% em 
relação a 2014 no número de matrículas de alunos com "deficiência, transtornos globais do desenvolvimento e/ou altas habilidades/superdotação em classes comuns (incluídos) ou em classes especiais exclusivas”. A educação brasileira sofreu mudanças com a introdução da educação inclusiva (SANTOS, 2018), e segundo Barbosa, Fialho e Machado (2018) ao ver cada indivíduo com suas peculiaridades e características permite a inclusão de grupos excluídos historicamente por meio da ampliação da participação no ensino regular e sua inserção social.

$\mathrm{Na}$ escola inclusiva todos são considerados iguais, incluir significa, entre outras coisas, a escola modificar sua forma de funcionamento para receber os diferentes alunos e que suas necessidades sejam atendidas, inclusive os que tem necessidades educativas especiais. Nesse contexto se encontra os surdos que enfrentam as maiores dificuldades quando se fala de inclusão, pois o ensino-aprendizagem baseia-se exclusivamente, na maioria das vezes, na comunicação oral (NOGUEIRA; CARNEIRO; SOARES, 2018).

A comunicação faz parte da necessidade dos seres humanos e sua efetividade é fundamental para o desenvolvimento das pessoas, por isso é necessário que se valorize os mecanismos capazes de possibilitar que pessoas com limitações venham a integrar o processo de comunicação. A LIBRAS (Língua Brasileira de Sinais) é uma língua oficializada pela lei $\mathrm{n}^{\circ}$ 10.436 de abril de 2002 e pelo Decreto Federal n ${ }^{\circ} 5.626$ de 22 de dezembro de 2005 como meio legal de comunicação e expressão oficial da comunidade surda no Brasil. A inclusão da LIBRAS na escola como componente curricular, o bilinguismo, tradutor e intérprete de libras/língua portuguesa permitiu uma ampliação dos direitos dos surdos no ensino regular (PASSOS; SANTOS; CAMPELO, 2018), possibilitando o desenvolvimento do mesmo.

Entretanto, segundo Mendonça et al. (2018), apesar da garantia de direitos a educação na Legislação aos surdos, existe ainda impedimentos quanto à implementação como o ensino de LIBRAS como disciplina curricular na Educação Básica, adaptação do currículo e uma formação pedagógica de forma a preparar para entender e conviver com o aluno surdo.

A Legislação garante às pessoas com necessidades especiais o direito ao Atendimento Educacional Especializado (AEE) preferencialmente no ensino regular. Dentro desse cenário de educação inclusiva, como um espaço, que respeita e considera as especificidades de cada aluno com deficiência possibilitando assim o maior acesso, permanência e desenvolvimento de suas potencialidades, que em consequência tornar-se um importante mecanismo facilitador de inclusão para uma educação de qualidade (FERREIRA, 2016).

A problemática dessa pesquisa voltou-se para responder ao seguinte questionamento: Como vem acontecendo a inclusão de alunos surdos nas escolas públicas do município em estudo? Como hipóteses, o estudo apresenta que: a) Apesar dos avanços na legislação que 
regulamenta a inclusão das pessoas surdas nos espaços formais de ensino, ainda existem muitas lacunas que corroboram para o seu fracasso escolar, b) As escolas apresentam estrutura precária para atendimento especializado ao surdo, c) $\mathrm{O}$ acompanhamento especializado dos alunos surdos não acontece regularmente.

Diante do exposto, o presente trabalho tem como objetivo analisar o espaço escolar das Escolas Públicas do Município de Uruçuí-PI quanto à estrutura física e de pessoal para o suporte aos alunos surdos, associando essa estrutura ao acesso, permanência e êxito desses estudantes.

\section{REFERENCIAL TEÓRICO}

$\mathrm{Na}$ antiguidade, até os anos de 1700, a sociedade apresentava comportamentos e percepções variadas em relação ao deficiente; a percepção da sociedade por concepções sociopolíticas aplica-se a todas as deficiências, pois eram vistas todos como iguais e não representavam potencial para a vida produtiva, por isso a sociedade da época não tinha interesse em ofertar serviços para o desenvolvimento dos deficientes, haja vista que a condição de incapacidade fazia parte da concepção da época. Nesse período, os serviços de atendimentos, quando havia, ocorriam em monastérios que ofereciam cuidados e amparo para as pessoas com deficiência e eram realizados por religiosos, no entanto, ainda não havia a preocupação com o desenvolvimento e o tipo de atendimento que era destinado para esse público, o que demonstra que esse eram de caráter assistencialista (MAZZOTTA, 2011).

$\mathrm{O}$ artigo 54 do Estatuto da Criança e do Adolescente (ECA) aponta determinações em relação ao ensino, com base no que estabelece o art. 208 da Constituição Federal de 1988: É dever do Estado assegurar à criança e ao adolescente: "I - ensino fundamental, obrigatório e gratuito, inclusive para os que a ele não tiveram acesso na idade própria; III - atendimento educacional especializado aos portadores de deficiência, preferencialmente na rede regular de ensino" (BRASIL, 2008, p.20).

$\mathrm{O}$ art. $3^{\circ} \mathrm{em}$ seu inciso IV da Constituição Federal de 1988 destaca como um dos seus objetivos fundamentais "promover o bem de todos, sem preconceitos de origem, raça, sexo, cor, idade e quaisquer outras formas de discriminação", e em se tratando da Educação, tem se a seguinte redação em seu artigo 208:

O dever do Estado com a educação será efetivado mediante garantia de: I- educação básica obrigatória e gratuita dos 4 (quatro) aos 17 (dezessete) anos de idade, assegurada, inclusive, sua oferta gratuita para todos os que a ela não tiveram acesso na idade própria; II- progressiva extensão da obrigatoriedade e gratuidade no ensino médio; III- atendimento educacional especializado aos portadores de deficiências, preferencialmente na rede regular de ensino (BRASIL, 1988).

Em matéria de legal de direitos, encontra-se na legislação nacional amparo às pessoas 
com deficiência o Estatuto da Criança e do Adolescente (Lei n. ${ }^{\circ} 8.069$ de 1990), quando estabelece em seu art. 53 que a criança e o adolescente têm direito à educação, visando ao seu pleno desenvolvimento, preparo para o exercício da cidadania e qualificação para o trabalho, com direito à: "I - igualdade de condições para o acesso e permanência na escola; II - direito de ser respeitado por seus educadores" (BRASIL, 2008, p.19).

A Lei de Diretrizes e Bases da Educação Nacional estabelece em seu art. $4^{\circ}$ que o Estado deve ofertar educação escolar pública mediante garantia de III - "atendimento educacional especializado gratuito aos educandos com deficiência, transtornos globais do desenvolvimento e altas habilidades ou superdotação, transversal a todos os níveis, etapas e modalidades, preferencialmente na rede regular de ensino".

O princípio da inclusão apela, portanto, para a educação inclusiva que pretende,
de um modo geral, que todos os alunos, com as mais diversas capacidades,
interesses, características e necessidades, possam aprender juntos, que seja dada
atenção ao seu desenvolvimento global (acadêmico, socioemocional e pessoal),
que, sempre que possível, todos os serviços educativos sejam prestados nas classes
regulares, que se crie um verdadeiro sentido de igualdade de oportunidades
(não necessariamente as mesmas oportunidades para todos) que vise o sucesso
escolar (CORREIA, 2001 p. 125).

São diversos os tipos de necessidades específicas que precisam de acompanhamento especializado nas instituições de ensino, entre essas, a surdez vem sendo discutida para que a comunicação nas escolas ocorra de modo que a aquisição do conhecimento e a interação aconteçam efetivamente.

Existem duas formas de se caracterizar a surdez, o modelo médico, em que ela é vista como uma deficiência, uma limitação de natureza patológica, com o surdo sendo rotulado por aquilo que não é capaz de fazer; ou seguindo a concepção sócio-antropológica da surdez, como uma diferença linguística, encarando o surdo a partir de suas possibilidades, que poderão ser mais ou menos aproveitadas em função da educação que lhe for ofertada (NOGUEIRA; CARNEIRO; SOARES, 2018).

Cultura surda é o jeito de o sujeito surdo entender o mundo e de modificá-lo a fim de torná-lo acessível e habitável, ajustando-o com as suas percepções visuais, que contribuem para a definição das identidades surdas e das "almas" das comunidades surdas. Isso significa que abrange a língua, as ideias, as crenças, os costumes e os hábitos do povo surdo (STROBEL, 2016, p. 29).

A Lei n. ${ }^{\circ}$ 10.436/2002, de 24 de abril, assegura às pessoas surdas a LIBRAS (Língua Brasileira de Sinais) como sua primeira língua, devendo os sistemas educacionais garantir a LIBRAS no ensino. Essa Lei representa um avanço na educação brasileira, posto que reconhece uma língua de sinais brasileira, a legitimidade e importância na cultura do surdo, (GARCIA, 
2015). Tavares e Carvalho (2010) destacam que esse mesmo dispositivo legal determinou que o poder público, bem como as empresas concessionárias de serviço público, devem garantir formas de apoiar o uso e a difusão da Libras como meio de comunicação objetiva e de utilização corrente das Comunidades Surdas do Brasil. Além disso, a mesma previu a inclusão do ensino de Libras nos cursos de Educação Especial, de Fonoaudiologia e de Magistério.

Apesar do avanço evidente nas políticas públicas no referente à inclusão escolar da pessoa surda, enxerga-se, ainda, a necessidade de se ampliar as pesquisas e as discussões sobre o papel dos profissionais da educação no processo e escolarização dos surdos objetivando implementar novas propostas que busquem, conforme Skliar (2005), a formação de professores disciplinado no respeito à Cultura Surda, a fim de contribuir para uma educação que leve o sujeito surdo ao êxito em seu processo de escolarização e inserção social. Nesse sentido, Leonel (2014) afirma que se visualizam, por meio da educação inclusiva, as tentativas em busca de igualdade de direitos, no entanto, ainda é necessário ser solidificadas.

\section{METODOLOGIA}

O estudo foi desenvolvido em todas as Escolas Públicas de Ensino Fundamental da zona urbana do Município de Uruçuí-PI no período de 03 de junho a 19 de julho de 2019, com a participação de nove escolas, sendo quatro da Rede Estadual e cinco da Rede Municipal de Ensino situadas em Uruçuí-PI.

Uruçuí é um município do estado do Piauí cuja atividade predominante atual é o agronegócio e por isso representa uma das cidades mais prósperas em crescimento econômico (IBGE, 2010).

De acordo com o IBGE (2010), o município de Uruçuí (Figura 1), possuía nesse ano uma população de 20.149 habitantes. Em 2016, sua renda per capita era de R \$36.777,46, representando a $685^{\mathrm{a}}$ posição nacional e a $2^{\mathrm{a}}$ posição do estado do Piauí. 
Figura 1: Localização do Município de Uruçuí.

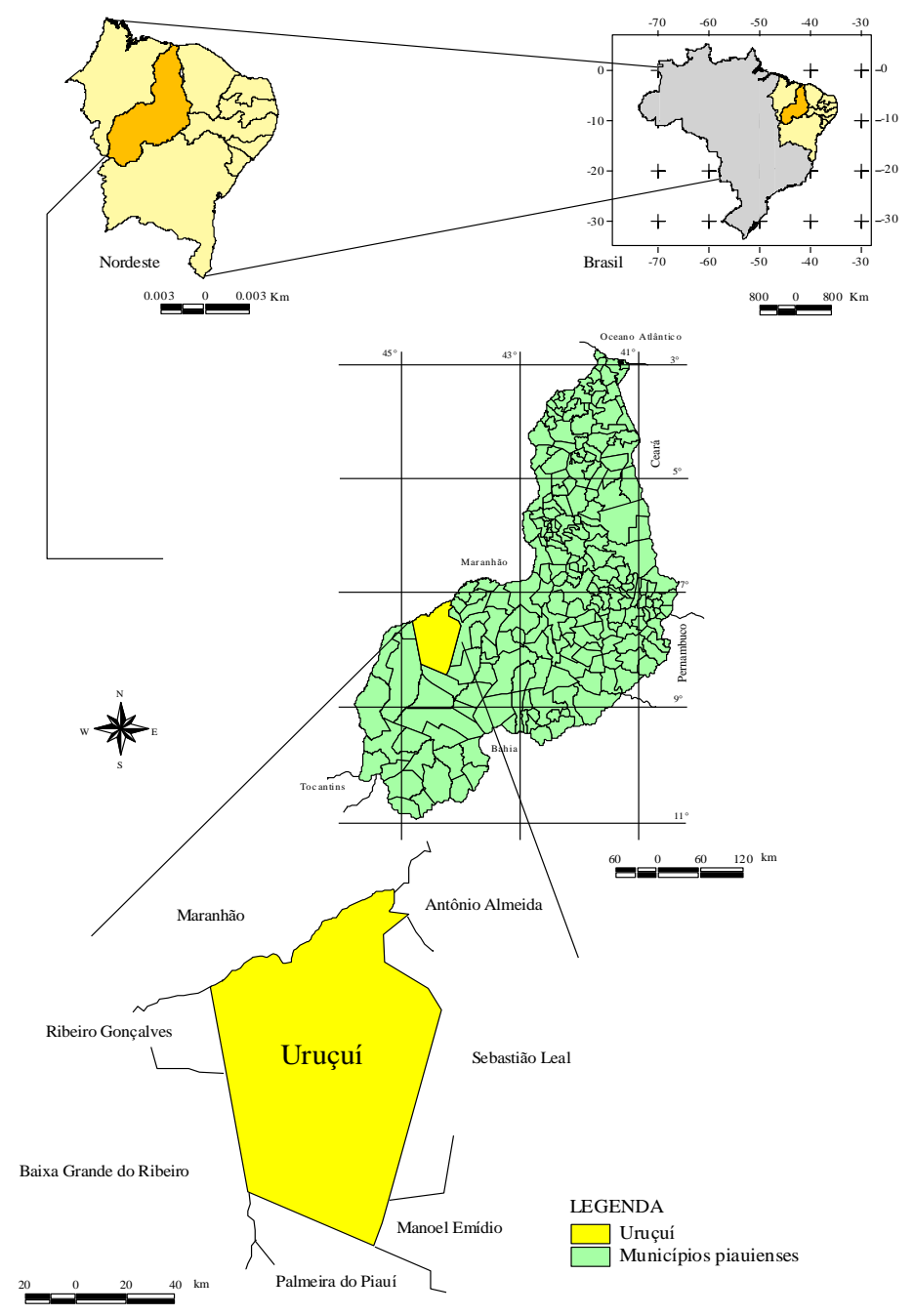

Fonte: IBGE (2010).

Esta pesquisa foi concretizada por meio de entrevistas com roteiro semiestruturado com oito questões, sendo três objetivas e cinco subjetivas, direcionadas conforme parâmetros descritos na tabela 1:

Tabela 1: Definição de categorias da pesquisa

\begin{tabular}{|c|c|c|}
\hline Categorias de variáveis & Unidade & Definição \\
\hline \multicolumn{3}{|l|}{ Quantitativas } \\
\hline $\begin{array}{l}\text { Matrículas de alunos } \\
\text { surdos }\end{array}$ & № de alunos & $\begin{array}{l}\text { Quantidade de alunos matriculados no } \\
\text { ensino fundamental das escolas pesquisadas } \\
\text { no período de } 2015 \text { a } 2019\end{array}$ \\
\hline $\begin{array}{l}\text { Projeção de aprovação de } \\
\text { alunos surdos }\end{array}$ & $\%$ & $\begin{array}{l}\text { \% de alunos surdos aprovados relativamente } \\
\text { ao número de ingressantes nos anos de } \\
2015 \text { a } 2018 \text {. }\end{array}$ \\
\hline \multicolumn{3}{|l|}{ Qualitativas } \\
\hline $\begin{array}{l}\text { Suporte disponível para os } \\
\text { alunos surdos }\end{array}$ & $\begin{array}{l}\text { Descrição do } \\
\text { suporte }\end{array}$ & $\begin{array}{l}\text { Disponibilização de recursos materiais ou } \\
\text { humanos para acompanhamento dos alunos } \\
\text { surdos }\end{array}$ \\
\hline Discussão e socialização & Sim ou não & Formas de realização de discussão e \\
\hline
\end{tabular}




\begin{tabular}{|l|c|l|}
\hline $\begin{array}{l}\text { da inclusão de alunos } \\
\text { surdos na comunidade } \\
\text { escolar }\end{array}$ & $\begin{array}{l}\text { socialização de alunos surdos na } \\
\text { comunidade escolar. }\end{array}$ \\
\hline $\begin{array}{l}\text { Limitação do acesso de } \\
\text { alunos surdos à Escola }\end{array}$ & $\begin{array}{c}\text { Fatores } \\
\text { limitantes }\end{array}$ & $\begin{array}{l}\text { Descrição de fatores que limitam o acesso } \\
\text { dos alunos surdos nas Instituições em estudo }\end{array}$ \\
\hline $\begin{array}{l}\text { Limitação da permanência } \\
\text { e do êxito de alunos } \\
\text { surdos }\end{array}$ & $\begin{array}{c}\text { Fatores } \\
\text { limitantes }\end{array}$ & $\begin{array}{l}\text { Descrição de fatores que limitam a } \\
\text { permanência e o êxito dos alunos surdos nas } \\
\text { Instituições em estudo. }\end{array}$ \\
\hline $\begin{array}{l}\text { Perspectiva de } \\
\text { contratação de intérprete } \\
\text { de Libras }\end{array}$ & Sim ou não & $\begin{array}{l}\text { Possibilidade de contratação de um } \\
\text { intérprete de Libras para acompanhamento } \\
\text { dos alunos surdos }\end{array}$ \\
\hline Libras no currículo & Sim ou não & $\begin{array}{l}\text { Planejamento para a introdução da disciplina } \\
\text { de libras como componente curricular }\end{array}$ \\
\hline
\end{tabular}

Fonte: Própria (2019)

Primeiramente foi lido e entregue aos representantes das escolas o Termo de Consentimento Livre e Esclarecido (TCLE), a fim de que fosse autorizada a participação da escola na pesquisa.

\section{RESULTADOS E DISCUSSÃO}

Os resultados que seguem refletem a realidade de nove escolas públicas do município de Uruçuí, estado do Piauí, no que se refere à implementação de políticas voltadas para o atendimento educacional de pessoas surdas na Rede Regular de Ensino das Escolas em estudo.

A figura 1 mostra o número de alunos surdos matrículas nas Instituições nos últimos cincos anos. Como se pode verificar, são apenas seis alunos regularmente matriculados de 2016 a 2019. Esses números, a priori, não refletem ausência ou presença de políticas públicas efetivas direcionadas para o atendimento especializado aos surdos nas instituições em estudo. Outrossim, mostra que há presença de alunos surdos nessas instituições e, portanto, há necessidade dessas políticas básicas como o intérprete de libras e condições para o êxito e a permanência na escola, o que será apresentado em análise posterior. 
Figura 2. Número de alunos surdos matriculados nos últimos cinco anos nas escolas entrevistados de ensino fundamental na cidade de Uruçuí - PI, Brasil.

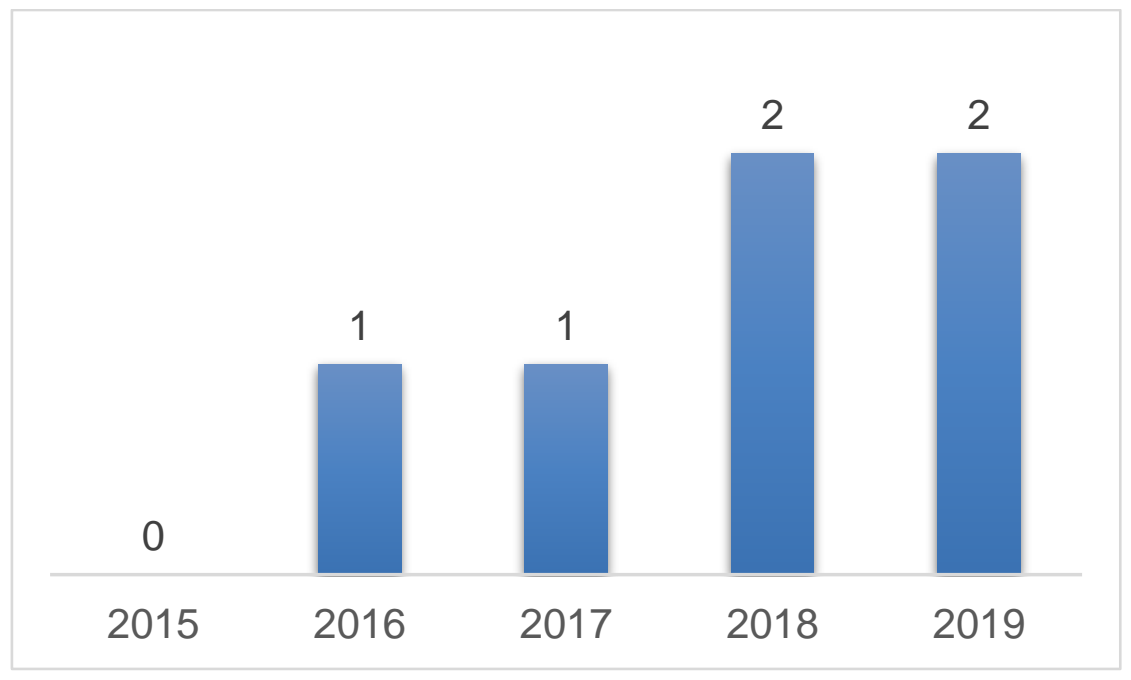

Fonte: Própria (2019).

Ao serem questionados quanto à projeção de aprovação de alunos surdos nas escolas onde há matrículas dos mesmos nos anos em estudo (2015 a 2018), todas as instituições informaram que sempre aprovam os alunos por apresentarem algum tipo de deficiência e entenderem que eles têm a garantia do direito à aprovação. Essa afirmação denuncia o quanto as escolas estão desqualificadas para recepção e integração dos alunos surdos ao processo educacional, uma vez que entendem que a garantia legal do direito à educação dos surdos de forma preferencial na Rede Regular de Ensino, restringe-se à aprovação do aluno, independentemente de seu progresso no campo do conhecimento ou da integração de forma promissora à sociedade.

Endossando essa visão, Sanches e Silva (2019), destacam que "a educação inclusiva requer de todos nós um esforço no que diz respeito à aprendizagem de todos os estudantes, promovendo o bem-estar acadêmico, emocional e social, favorecendo assim o seu desenvolvimento global”. Nesse sentido, não se pode limitar a educação à prática de aprovação, desvinculando-se da responsabilidade com a formação para o exercício da cidadania plena.

Quando indagado aos gestores das instituições a respeito do tipo de suporte oferecido para os alunos surdos em sala de aula, como descrito na figura 2 , seis das instituições afirmaram que há acompanhamento individualizado para os alunos que apresentam algum tipo de deficiência, por meio do apoio às atividades por um profissional da educação sem formação em libras, e as outras três escolas afirmaram não oferecer nenhum suporte aos alunos surdos. Cabe destacar, que nenhuma das escolas realizavam oficinas com os alunos para introduzir a libras e tão pouco apresentava um intérprete de libras durante as aulas ou um acompanhamento 
individualizado por meio do apoio as atividades por um profissional de libras.

Nesse sentido, enfatiza-se que o apoio aos estudantes surdos deve ocorrer por meio de um intérprete de libras, que deve acompanhar todas as aulas ministradas pelos professores fazendo a tradução português/libras (BRASIL, 2005).

"A falta de intérpretes, o despreparo dos professores, o preconceito e discriminação e a falta ou o uso inadequado do material didático pedagógico para este alunado, como por exemplo, filmes legendados, aulas sem material de apoio visual" são fatores que contribuem para o fracasso escolar dos alunos surdos (ANSAY, 2009, p. 114).

Destaca-se que os profissionais da educação que fazem o Atendimento Educacional Especializado nas escolas em estudo que mencionaram a existência desse apoio, são pedagogos que exercem entre outras atribuições, a função de acompanhar as atividades dos discentes surdos. Entretanto, não passaram por formação continuada para qualificação específica, havendo, portanto, a necessidade de as escolas reverem suas práticas à luz dos novos referenciais pedagógicos da inclusão.

Figura 3. Suportes para os alunos surdo nas escolas em estudo.

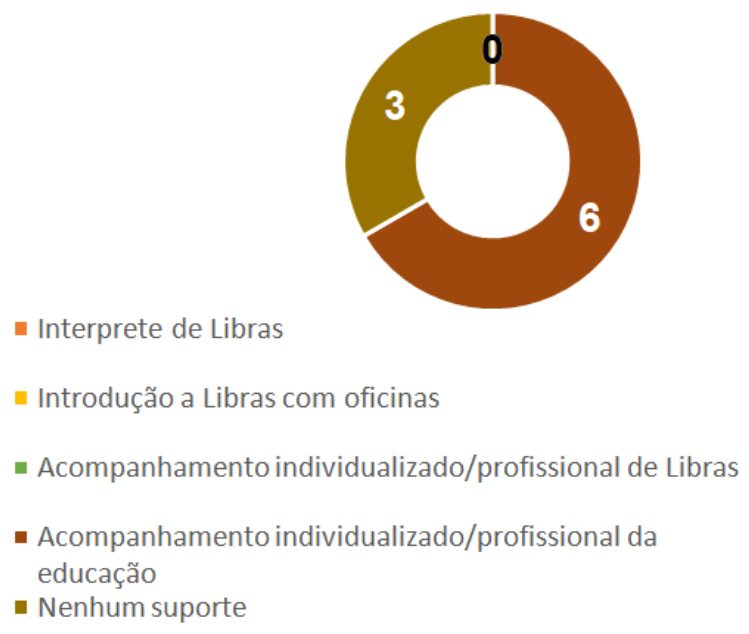

Fonte: Própria (2019)

Em seguida, questinou-se ao gestor se a instituição discutia a inclusão dos alunos surdos na comunidade escolar e, em caso afirmativos, os meios utilizados para esse fim:

$\checkmark$ Três escolas afirmaram descutir o tema em reuniões, palestras e encontros pedagogicos;

$\checkmark$ Uma relatou discutir somente com o corpo docente;

$\checkmark$ Cinco afirmaram não discutir sobre a inclusão de alunos surdos, alegando ser por conta de não possuir esse público matriculado na instituição.

Ao observar as respostas associadas às instituições, no que se refere à discussão da 
inclusão das pessoas surdas, verifica-se que não ocorre de maneira ampla envolvendo toda a comunidade acadêmica, o que seria o ideal, visando à difusão da ideia de que a surdez é apenas uma diferença linguística e, para que pessoas com limitação auditiva possam ser integradas efetivamente à sociedade, sua primeira língua precisa fazer parte primeiramente das organizações educacionais, tendo em vista se tratar de um direito assegurado em lei, para posteriormente passar a fazer parte, de forma progressiva, do dia-dia de todos os cidadãos.

Compreender as necessidades e especificidades de cada educando em uma sala de aula é essencial para o processo de ensino aprendizagem produtivo e inclusivo, assim é preciso que se entenda a cultura das pessoas surdas e que se tenha consciência da importância da introdução da Libras no desenvolvimento educacional destas, pois sendo sua primeira língua precisa ser assegurada, além disso introduzir a libras no ensino é uma forma de ajudar na aprendizagem de um conteúdo ministrado e traz igualdade entre os surdos e os demais alunos da turma. É indispensável que sejam procuradas formas de incluir a todos, uma vez que toda pessoa tem direito a educação, levando em consideração suas necessidades, habilidades e interesses de aprendizagem (SILVA, 2018).

Para Borges e Nogueira (2016), a escola é uma ferramenta de suma importância para vencer/superar a exclusão, ao possibilitar como objetivo uma educação democrática. É importante que a escola seja acessível para todos, independentemente de suas potencialidades ou deficiências. Quando um aluno surdo se introduzir no contexto escolar, é necessária a parceria conjunta de escola e família para promover uma formação surda para a vida em sociedade.

Ao serem questionados sobre os principais fatores que limitam o igresso do aluno surdo na instituição, obteve-se o seguinte resultado:

$\checkmark$ Quatro das escolas relataram ser a falta de profissionais especializados para o acompanhamento dos alunos surdos;

$\checkmark$ Duas afirmaram ser a comunicação entre professor e o aluno surdo;

$\checkmark$ Uma escola afirmou ser a falta de capacitação/qualicação e empenho dos familiares;

$\checkmark$ Uma escola afirmou tratar-se de falta de locomoção/tranporte;

$\checkmark$ Uma escola relatou nenhuma limitação.

Das respostas acima apresentadas associadas à concepção dos gestores, é relevante destacar queo fator limitante que apareceu com maior frequência foi a falta de profissional de libas, seguido da ineficiência da comunicação docente/discente surdo, corroborando com o que se encontra na literatura atual. De acordo com Sanches e Silva (2019), é necessário que o 
professor esteja preparado através de uma formação que permita abordar em sala de aula a valorização da heterogeneidade, a cultura surda, a Libras entre outros, pois as dificuldades de inclusão dos alunos surdos frequentemente estão relacionadas ao processo de ensinoaprendizagem. A parceria do professor-intérprete de Libras em sala de aula é de extrema importância para o desenvolvimento do aluno surdo (SANCHES; SILVA, 2019).

Já a concepção dos gestores sobre os principais fatores que limitam o êxito e permanência do aluno surdo na instituição (Figura 4), obteve-se maior frequência associada à ausência de profissionais qualificados para acompanhar esse aluno no âmbito escolar, seguida da falta de incentivo institucional e a falta de apoio pedagógico aos professores.

Genericamente, pode-se afirmar que a inclusão dos alunos surdos não acontece na prática, pois existe a ausência de proposta/atitudes para um ensino que supere e permita o ensino independente das diferenças entre ouvintes e surdos, tornando a inclusão uma realidade (BORGES; NOGUEIRA, 2016).

Muitas barreiras e dificuldades são enfrentadas pelas escolas para permanência do aluno com deficiência, porque não basta fazer a matrícula desses alunos, ele possui direitos e especificidades que a instituição de ensino precisa atender, não somente para aprendizagem dos conteúdos, mais também para integração dos alunos surdos com os demais. Então oferecer recursos para que o aluno com surdez possa permanecer e se devolver em todas as suas instâncias, seja de cunho moral, intelectual ou física, deve ser vista como prioridade pelas políticas públicas (CARNEIRO, 2018).

Figura 4. Principais fatores que limitam o êxito e a permanência do aluno surdo nas escolas em estudo

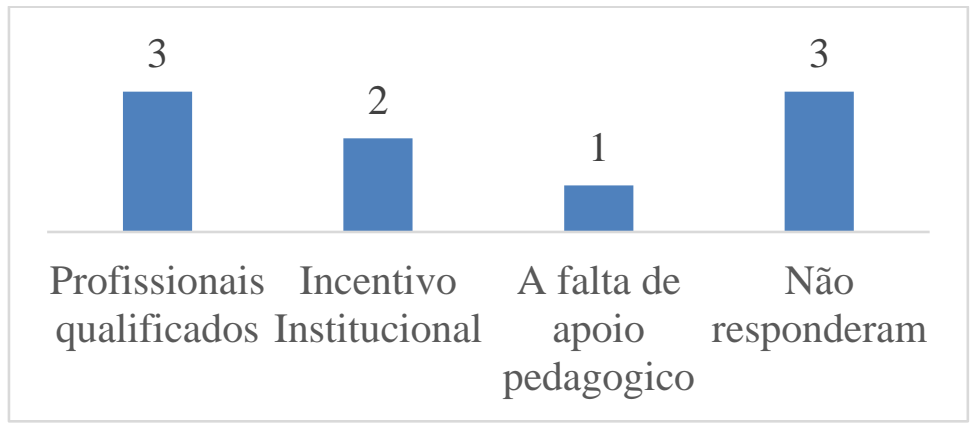

Fonte: Própria (2019)

Na questão seguinte, indagou-se aos gestores sobre a existência de perspectiva para a contratação de um intérprete de libras, caso ainda não exista na Instituição. Verificou-se que todas as escolas não dispõe de intérprete de Libras e a maioria afirmou não ter a perspectiva de contratação, duas das escolas que atualmente não possui matrícula de alunos surdo relatou que poderia contratar, e que dependeria da efetivação dessa matrícula, e uma outra escola relatou 
responsabilidade seria repassada a Secretaria Municipal de Educação, não tendo propriedade para precisar a resposta.

É importante a presença dos interpretes para o aluno surdo, pois esses profissionais possuem habilidades e competências para lidar com esse aluno atendendo as suas necessidades e especificidade da linguagem, pois a comunicação é essencial para a convivência em qualquer ambiente. $\mathrm{O}$ que tem se observado é que apesar da existência de cursos de formação específica para tradutor/intérpretes de libras, quem atua nessa área na maioria das vezes são licenciandos aprovados em exames de proficiência para Libras. Algo que merece atenção das políticas educacionais, pois o aluno surdo que não domina a língua utilizada pela maioria da sala de aula, principalmente pelo professor, depende exclusivamente da Libras para seu aprendizado (BORGES; NOGUEIRA, 2016).

Dessa forma, apesar do reconhecimento da Libras como língua oficial das pessoas com surdez ser recente precisa-se cada vez mais compreender a importância do intérprete de Libra no contexto educacional para a comunicação do aluno surdo, pois seu papel se relaciona com a interação social e cultural para inclusão e inserção dos surdos na sociedade (SOUSA, 2015).

$\mathrm{Na}$ última questão, solicitou-se aos gestores que respondesse se havia perspectiva de introdução da disciplina Libras como componente curricular, contatou-se que todas as escolas não tinham perspectiva de adicionar a disciplina na matriz curricular. Isso é algo que deveria ser repensado e levado em consideração a introdução da disciplina Libras mesmo no ensino básico, uma vez que Libras é a língua natural utilizada pelos surdos brasileiros para se comunicar, dessa forma é importante que essa disciplina seja estudada junto com as outras para que a criança surda possa conviver e aprender a melhorar a interação ouvinte e surdo, além de melhorar seu rendimento escolar (SILVA, 2018).

Segundo Borges, Rocha e Justi (2017) a escola precisa criar mecanismos e suportes, considerando a prática pedagógica da educação inclusiva, o aluno surdo não somente precisa estar na sala de aula com os demais, mais o acolhimento a esse público vai além disso, suas especificidades educacionais especiais precisam ser compreendidas e levadas em conta para seu efetivo desenvolvimento. Assim seu aprendizado necessita de um acompanhamento especializado com um professor com formação em Libras.

\section{CONCLUSÕES}

As escolas em análise recebem as matrículas de alunos surdos, porém a aprendizagem fica comprometida, visto que os resultados mostraram que as escolas de ensino fundamental do município de Uruçuí-PI não dispõem de estrutura favorável ao desenvolvimento do ensino 
inclusivo das pessoas surdas. Tal afirmação é possível a partir da análise da inexistência de profissional de libras em salas com surdos matriculados, bem como do déficit de recursos tecnológicos voltados à facilitação da comunicação com os alunos com surdez.

Além disso, as ações voltadas para a inclusão de alunos com surdez não ocorrem com frequência no ambiente escolar; a discussão sobre a temática não vem sendo difundida amplamente com a comunidade acadêmica, o que caminha em desacordo com a legislação vigente sobre a matéria, uma vez que desde 2002 já existe legislação específica direcionada para orientação de ações que visam à inclusão integral de pessoas surdas.

Assim, é preciso que a sociedade cobre a concretização da execução das políticas públicas asseguradas em lei aos alunos surdos no âmbito escolar, uma vez que o poder público vem negligenciando essa prática.

\section{REFERÊNCIAS}

ANSAY, N. A trajetória escolar de alunos surdos e a sua relação com a inclusão no ensino superior (Dissertação de mestrado). Universidade Federal do Paraná, 2009, Brasil.

BARBOSA, D. S., FIALHO, L. M. F., MACHADO, C. J. S. Educação inclusiva: aspectos históricos, políticos e ideológicos da sua constituição no cenário internacional. Actualidades Investigativas en Educación. v. 18, n. 2, 2018.

BORGES, A. S.; ROCHA, J. S.; JUSTI, J. Inclusão Educacional Do Aluno Surdo: Uma Perspectiva Social E Reflexiva. Professares, v. 6, n. 3, 2017.

BORGES, F. A.; NOGUEIRA, C. M. I. O ensino e a aprendizagem de Matemática para surdos inclusos: o que dizem os intérpretes de Libras?. Educação matemática em revista-RS, v. 2, n. 17, 2016.

BRASIL. Estatuto da Criança e do Adolescente. Diário Oficial da União. Brasília. Imprensa Oficial, 13 de julho de 1990.

BRASIL. Ministério da Saúde. Estatuto da Criança e do Adolescente / Ministério da Saúde. 3. ed. - Brasília: Editora do Ministério da Saúde. 2008.

BRASIL. Lei de Diretrizes e Bases da Educação Nacional. Lei n ${ }^{\circ}$ 9394/96 de 20 de dezembro de 1996, Brasília, 1996.

BRASIL. Constituição da República Federativa do Brasil. Brasília: Gráfica do Congresso Nacional, 1988.

CARNEIRO, M. R. I. Acessibilidade espacial em escolas municipais: estudo de caso da escola de educação básica Elizabeth Ulyssea Arantes, no município de Laguna. TCC (Trabalho de Conclusão de Curso) - Engenharia Civil-Tubarão, 2018.

CORREIA, L. Educação inclusiva ou educação apropriada? In D. Rodrigues 
(Org.), Educação e diferença: Valores e práticas para uma educação inclusiva (pp. 123-142). Porto: Porto Editora, 2001.

FERREIRA, D. C. K. Salas de Atendimento Educacional Especializado (AEE) na rede regular pública de ensino paranaense: desafios, limites e possibilidades do paradigma inclusivo. Revista Educação Especial, v. 29, n. 55, 2016.

GARCIA, E. C. O que todo pedagogo precisa saber sobre LIBRAS: Os principais aspectos e a importância da Língua Brasileira de Sinais. Rio de Janeiro: Wak, 2015.

Instituto Brasileiro de Geografia e Estatística (IBGE - 2010). Cidades. Disponível em: https://cidades.ibge.gov.br/brasil/pi/urucui/panorama. Acesso em: 20 jun. 2019.

INEP. Censo Escolar 2018 revela crescimento de $18 \%$ nas matrículas em tempo integral no ensino médio,2018. Brasília: MEC, 2019.

LEONEL, W.H.S. O processo de escolarização do deficiente intelectual da educação básica e os desafios da prática docente: um debate relevante ao ensino superior. 2014. Dissertação (Mestrado em Psicologia) - Universidade Estadual de Maringá, Departamento de Psicologia. Maringá, 2014.

LEONEL, W.H.S. Politicas e o Processo Ensino Aprendizagem na Educação Inclusiva. Reimpressão Maringá-PR.: UniCesumar, 2018. 228 p.

MENDONÇA, L. M.; CARVAlHO, T. W.; DOMINGUES, L. S.; FARIA, A. C. C. A importância da LIBRAS como Componente Curricular na Educação básica. Educação: Saberes e Prática, v. 7, n. 1, 2018.

MOZZATA, M. J. S.. Educação Especial no Brasil: História e Políticas Públicas. $6^{\text {a }}$. Ed. São Paulo: Cortez, 2011.

NOGUEIRA, C. M. I.; CARNEIRO, M. I. N.; SOARES, B. I. N. LIBRAS. Maringá-Pr.: UniCesumar, 2018.

PASSOS, Y.; SANTOS, W.; CAMPELO, W. Língua de sinais na escola: comunicação como forma de interação entre surdos e ouvintes por meio da LIBRAS na Escola Luiz Nunes de Direito. Littera on line, v. 9, 2018.

SANCHES, I.; SILVA, P. B. A inclusão de estudantes surdos no ensino superior brasileiro: o caso de um curso de Pedagogia. Revista Portuguesa de Educação, v. 32, n. 1, 2019.

SANTOS, M. C. D. O direito das pessoas com deficiência à educação inclusiva e o uso pedagógico dos recursos de tecnologia assistiva na promoção da acessibilidade na escola. InFor, v. 1, n. 1, 2016.

SILVA, A. R. As libras e as contribuições para a inclusão dos surdos nas aulas de Geografia. 2018. 35f. Trabalho de Conclusão de Curso (Graduação em Geografia) Universidade Estadual da Paraíba, Guarabira, 2018.

SOUSA, V. A importância do papel do intérprete de libras no processo de aprendizagem do 
aluno surdo em sala de aula nas escolas de ensino comuns. Cadernos da FUCAMP, v. 14, n. $20,2015$.

STROBEL, K. As imagens do outro sobre a cultura surda. Florianópolis: Ed. da UFSC, 2016.

SKLIAR, Carlos (org.). A surdez: um olhar sobre as diferenças. 3. ed. Porto Alegre: Mediação, 2005.

TAVARES, I. M. S; CARVALHO, T. S. S. Inclusão escolar e a formação de professores para o ensino de Libras (LÍNGUA BRASILEIRA DE SINAIS): Do texto oficial ao contexto. São Paulo: Ed. da Vepeal, 2010. 